REVIEW

\title{
Exploiting the antidiabetic properties of incretins to treat type 2 diabetes mellitus: glucagon-like peptide 1 receptor agonists or insulin for patients with inadequate glycemic control?
}

\author{
Luc F Van Gaal, Stephen W Gutkin ${ }^{1}$ and Michael A Nauck ${ }^{2}$ \\ Department of Diabetology, Metabolism and Clinical Nutrition, Antwerp University Hospital, Wilrijkstraat 10 B-2650 Edegem, Antwerp, Belgium, \\ ${ }^{1}$ Rete Biomedical Communications Corp., Ridgewood, New Jersey, USA and ${ }^{2}$ Diabeteszentrum Bad Lauterberg, D-37431 Bad Lauterberg IM Harz, \\ Germany \\ (Correspondence should be addressed to L F Van Gaal; Email: luc.van.gaal@uza.be)
}

\begin{abstract}
Type 2 diabetes mellitus is associated with progressive decreases in pancreatic $\beta$-cell function. Most patients thus require increasingly intensive treatment, including oral combination therapies followed by insulin. Fear of hypoglycemia is a potential barrier to treatment adherence and glycemic control, while weight gain can exacerbate hyperglycemia or insulin resistance. Administration of insulin can roughly mimic physiologic insulin secretion but does not address underlying pathophysiology. Glucagon-like peptide 1 (GLP-1) is an incretin hormone released by the gut in response to meal intake that helps to maintain glucose homeostasis through coordinated effects on islet $\alpha$ - and $\beta$-cells, inhibiting glucagon output, and stimulating insulin secretion in a glucose-dependent manner. Biological effects of GLP-1 include slowing gastric emptying and decreasing appetite. Incretin mimetics (GLP-1 receptor agonists with more suitable pharmacokinetic properties versus GLP-1) significantly lower hemoglobin A1c, body weight, and postprandial glucose excursions in humans and significantly improve $\beta$-cell function in vivo (animal data). These novel incretin-based therapies offer the potential to reduce body weight or prevent weight gain, although the durability of these effects and their potential long-term benefits need to be studied further. This article reviews recent clinical trials comparing therapy with the incretin mimetic exenatide to insulin in patients with oral treatment failure, identifies factors consistent with the use of each treatment, and delineates areas for future research.
\end{abstract}

European Journal of Endocrinology 158 773-784

\section{Introduction}

Type 2 diabetes mellitus (T2D) causes substantial mortality, morbidity, and healthcare expenditures (1). T2D results when insulin secretion by the endocrine pancreas fails to compensate for insulin resistance in peripheral tissues. Once T2D has been diagnosed, $\beta$-cell function is reduced by up to $50 \%(2,3)$. Achieving tight glycemic control reduces risks of vascular complications. Epidemiologically, for every $1 \%$ increase in hemoglobin A1c (HbA1c) above $5.0 \%$, there is a $20 \%$ rise in cardiovascular risk (4). There is no evident threshold below which decreases in mean HbAlc values are not associated with further reductions in vascular risk (5-8).

Given the progressive nature of $\beta$-cell dysfunction (9), treatments often escalate, with lifestyle modifications (diet and exercise) giving way to monotherapy with an oral hypoglycemic agent (OHA), then combination of $\mathrm{OHA}$ regimens $(10,11)$. Under conventional treatment paradigms, insulin is introduced when OHAs fail to maintain adequate glycemic control. However, some insulin regimens and other therapies may not always adequately control postprandial glucose (PPG) excursions and may be associated with hypoglycemia and/or weight gain (12-16). Fear of hypoglycemia is considered a barrier to treatment adherence and overall glucose control $(17,18)$ and has been associated with reduced patient-reported well-being and perceived health status (19). Weight gain may be particularly undesirable, in that up to $80 \%$ of patients with T2D are overweight or obese $(20,21)$, and increasing obesity may worsen insulin resistance and otherwise increase cardiovascular risk and disease burden (22-25). Finally, neither any available OHA nor insulin effectively counters the 'steady, relentless decline in pancreatic ( $\beta$-cell) function' $(26,27)$ associated with T2D.

Given these factors, there is an interest in therapies that are weight neutral (or promote weight loss in overweight patients), minimize the risk of hypoglycemia, and exploit physiologic mechanisms to modify T2D. Before the advent of agents exploiting the enteroinsular (incretin) axis, only half of Unger's bihormonal (i.e., insulin and glucagon) hypothesis (28) of T2D pathophysiology had been addressed. Through the coordinated actions of glucagon and insulin, the healthy endocrine pancreas maintains glucose homeostasis, preventing both hyper- and hypoglycemia (29). 
Incretins, including glucagon-like peptide 1 (GLP-1), are hormones released by entero-endocrine cells in the gut in response to meals. GLP-1 helps to maintain glucose homeostasis through concerted effects on islet $\alpha$ - and $\beta$-cells. Glucose-dependent insulinotropic polypeptide (previously termed gastric inhibitory polypeptide, GIP) and GLP-1 stimulate insulin secretion in a glucose-dependent manner (i.e., only in the presence of raised blood glucose). GLP-1 stimulates insulin secretion in a glucose-dependent fashion and can inhibit glucagon secretion, lower plasma glucose and $\mathrm{HbA1c}$, inhibit gastric emptying, and decrease appetite and energy intake (30-34).

These and other findings have helped to spawn the development of incretin mimetics. Given the pivotal role of $\beta$-cell dysfunction in the progressive nature of T2D, the fact that certain incretin mimetics promote $\beta$-cell replication/neogenesis/mass in animal models is promising from the standpoint of modifying the pathophysiology of this condition $(35,36)$. The fact that incretin mimetics may help to enhance glycemic control as well as provide weight loss (or a weightneutral profile) is also promising for many of the T2D patients who are overweight or obese.

This article focuses on endogenous incretins, provides an overview of current and emerging incretin mimetics, reviews data comparing treatment with the incretin mimetic exenatide or with insulin, identifies patient factors consistent with the use of incretin mimetics or insulin, and identifies potential areas for future clinical research. Although certain oral incretin enhancers (dipeptidyl peptidase 4 (DPP-4) inhibitors), such as sitagliptin and vildagliptin, are effective and well-tolerated agents that improve glycemic regulation, these medications have not been evaluated as alternatives to insulin therapy and are not included in the present article (for recent reviews, see Drucker (37) and Åhren (38)).

\section{Incretins in physiologic perspective}

Nutrient intake triggers the secretion of gastrointestinal (GI) hormones that play a part in regulating gut and gallbladder motility, digestive enzyme secretion, and postprandial carbohydrate metabolism. Incretin hormones stimulate secretion of insulin by the endocrine pancreas. Through the actions of these hormones, enteral nutrition results in a more potent insulinotropic stimulus compared with an isoglycemic i.v. challenge and this has been termed the 'incretin effect' (39-41).

GLP-1 is a 30-amino acid peptide synthesized and secreted by L-cells mainly within the distal small intestine (ileum) in response to meal intake; it exerts potent effects on GI motility and islet secretory activity, such as delaying gastric emptying and increasing $\beta$-cell secretory activity and reducing $\alpha$-cell secretory activity. GLP-1 exists principally as an amidated form (GLP-1 (7-36) amide) and also as a glycine-extended form
(GLP-1 (7-37)) (42), although both forms have similar biological properties and are equipotent as incretins (43). GIP is a 42-amino acid peptide generated by K cells in the proximal small intestine (duodenum and jejunum), although there is considerable colocalization of GLP-1- and GIP-secreting cells as well as enteroendocrine cells secreting both GLP-1 and GIP $(44,45)$.

The effects of GIP and GLP-1 on glycemic regulation are transduced via widely distributed specific G-proteincoupled receptors, which can increase intracellular cAMP and calcium concentrations for signal transduction (46). Activation of GIP receptors, which are mainly expressed on islet $\beta$-cells, adipocytes, and cells in the central nervous system (CNS), among other actions, helps to prevent apoptosis and foster survival of human $\beta$-cells (47).

Activation of GLP-1 receptors amplifies these effects on glycemic regulation, as well as decreasing glucagon secretion, slowing gastric emptying, promoting a sense of satiety, and reducing caloric intake. Potentially beneficial effects of physiologic incretins (and incretin mimetics) on body weight may be mediated through effects on the CNS and adipocytes. Administration of GLP1 into the cerebral ventricles of rats sharply decreased their energy intakes (48). These effects may have been mediated by interactions of central GLP-1 (released from noncatecholaminergic neurons in the solitary tract nucleus (49)) with hypothalamic and extrahypothalamic nuclei in the brain, as well as via peripheral GLP-1, which can reach the area postrema and subfornical organs with access to hypothalamic centers controlling energy intake (50).

Receptors for glucagon and physiologic incretins (e.g., GIP) are present on adipocytes in animals, but it is not clear if they are also present on human adipocytes; these receptors may play a role in fat metabolism, with GIP promoting lipolysis (51-56). These receptors are downregulated in certain animal models of T2D. GIP may promote lipolysis partly by stimulating lipoprotein lipase receptors on adipocytes (57).

In addition to increased energy intake and adiposity, many physiologic defects associated with T2D can be addressed via GLP-1 and pharmacotherapies (incretin mimetics and enhancers) derived from the enteroinsular axis (Fig. 1) (46). However, GLP-1 itself has a short plasma half-life and is not well suited to intermittent administration.

\section{Overview of current and emerging therapies exploiting the entero-insular axis: incretin mimetics}

The insulinotropic effects of GIP are attenuated in patients with T2D, who may experience postprandial elevations in circulating glucagon secondary to reduced postprandial suppression of glucagon by insulin within the endocrine pancreas; these findings are based in part on early work by Samols and colleagues on intra-islet endocrine regulation $(58,59)$. Therefore, pharmacologic strategies that exploit 


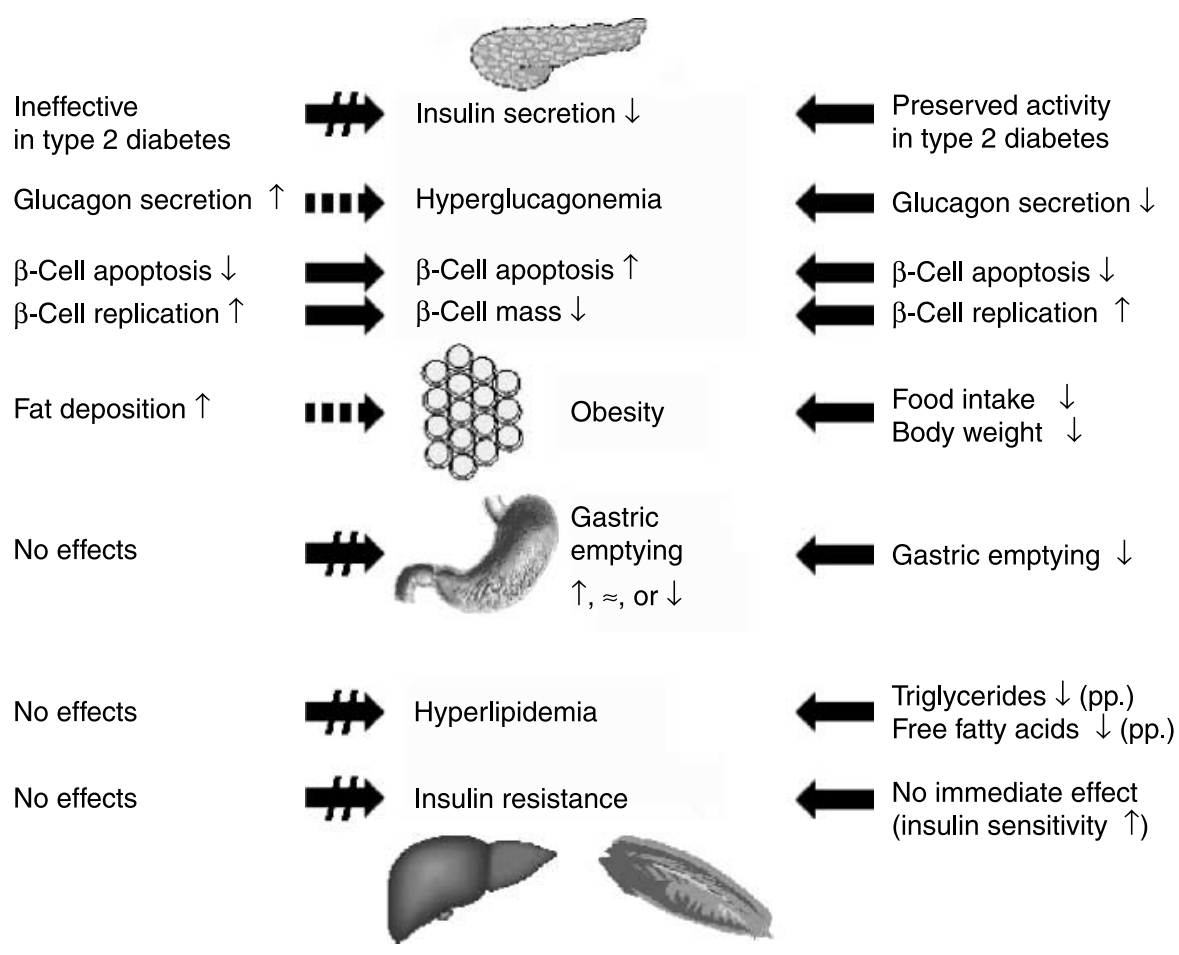

Figure 1 Biological actions of the incretin hormones GIP and GLP-1 addressing central aspects of the pathophysiology of type 2 diabetes. Actions considered to be potentially beneficial for patients with type 2 diabetes are shown as solid arrows, potentially harmful as dashed arrows, and without effect as slashed arrows. Overall, GLP-1 in many aspects exerts biological activity that may be considered therapeutic for patients with type 2 diabetes. For more details and references, see review by Drucker \& Nauck (46). GLP-1, glucagon-like peptide 1; GIP, glucose-dependent insulinotropic polypeptide (gastric inhibitory peptide); pp., postprandial.

the entero-insular axis have centered on GLP-1. Incretin mimetics include exenatide (Byetta, Amylin Pharmaceuticals, San Diego, CA, USA; Eli Lilly), a 39-amino acid peptide amide previously termed AC2993 (60-72). Other incretin mimetics include the investigational agents liraglutide (73-78), which is also known as NN2211 (Novo Nordisk, Bagsvaerd, Denmark), and a human recombinant GLP-1-albumin conjugate (known as albugon; GlaxoSmithKline, Human Genome Sciences) (79, 80) and the GLP-1 receptor agonist ZP10 (Sanofi-Aventis, Bridgewater, NJ, USA), of which a prolonged-release formulation is being investigated.

\section{Exenatide}

Exenatide is the name for a synthetic product identical to exendin-4, a peptide discovered and named by Raufman and Eng because it was isolated from an exocrine (salivary) gland of lizards (Heloderma species) but exerted endocrine effects when administered to mammals $(43,81)$. This GLP-1 receptor agonist shares $\sim 50 \%$ sequence identity with mammalian GLP-1 but is DPP-4-resistant and longer lived (mean $t_{1 / 2}=3.3-4.0 \mathrm{~h}$ (82)) with plasma concentrations remaining elevated for up to $6 \mathrm{~h}$ after an s.c. injection $(67,82,83)$.
Placebo-controlled clinical trials involving s.c. exenatide 5-10 $\mu \mathrm{g}$ administered before breakfast and dinner have evaluated the efficacy and tolerability of exenatide plus OHAs compared with OHAs alone, including metformin (84), sulfonylureas (85), and sulfonylureas together with metformin (86) for $\geq 16$ weeks. These studies involved a total of 1680 patients, most of whom were men and Caucasian, with mean ages ranging from 53 to 59 years and HbA1c from 7.9 to $8.6 \%$ (26). In an analysis of exenatide, $10 \mu \mathrm{g}$ treatment twice daily together with metformin and/or a sulfonylurea in individuals with T2D and suboptimal glycemic control on OHAs (mean HbAlc=8.2\%), 217 patients completing 3 years of therapy had a sustained reduction of $1.0 \%$ in HbA1c (87). Weight loss from baseline was progressive, reaching $5.3 \mathrm{~kg}$ at 3 years $(P<0.0001$ versus baseline and versus 30 weeks) in these patients (baseline mean body mass index $(\mathrm{BMI})=33.5 \mathrm{~kg} / \mathrm{m}^{2}$ ). However, only a highly selected subgroup of patients was followed up for 3 years.

The foregoing findings were from an open-label extension study involving patients receiving only exenatide twice daily. However, other clinical data are available to compare the effects of exenatide with placebo on body weight. In 30-week-controlled clinical trials 
involving patients with BMI values of $27-45 \mathrm{~kg} / \mathrm{m}^{2}$, treatment with exenatide $10 \mu \mathrm{g}$ twice daily resulted in a mean weight loss of 1.6-2.8 kg compared with a mean loss of $0.6-0.9 \mathrm{~kg}$ on placebo $(P \leq 0.05$ for each comparison of active treatment versus placebo) (8486). Decreases in body weight tended to be somewhat more pronounced in patients with baseline $\mathrm{BMI} \geq 30$ compared with $<30 \mathrm{~kg} / \mathrm{m}^{2}(84)$.

Across a number of studies (84-86), the weighted mean difference for the absolute change in $\mathrm{HbAlc}$ with exenatide compared with placebo was statistically significant at -1.0 percentage point $(95 \%$ confidence interval $(\mathrm{CI})=-1.2$ to $-0.8 \%)$ (26). Other weighted mean differences for exenatide (versus placebo) based on a recent systematic review and meta-analysis included a significant 4.2 risk ratio for achieving $\mathrm{HbAlc}<7.0 \%$, an $\sim 1.5 \mathrm{mmol} / \mathrm{l}(27 \mathrm{mg} / \mathrm{dl})$ decrease in fasting glucose (FG), and a $1.4 \mathrm{~kg}$ decrease in body weight (26). In these studies, nausea occurred in 36 to $51 \%$ of patients receiving exenatide but was typically mild or moderate, declined in frequency after the first 2 months of treatment, and infrequently (in $\sim 5$ to $6 \%$ of patients) led to treatment discontinuation (84-86).

As with exogenous GLP-1, adverse effects associated with exenatide were chiefly of GI origin, including nausea (and, less frequently, vomiting), which was mostly mild or moderate and typically occurred soon after treatment was initiated or doses increased. However, these adverse effects have resulted in relatively few patients discontinuing exenatide; for instance, in three studies, the proportion of exenatide-treated patients who discontinued because of nausea ranged from $\sim 5$ to $6 \%$ during exenatide treatment for 30 weeks to 2 years $(84,85,88)$. The incidence of nausea can be reduced via progressive (stepwise) escalation of exenatide doses (89). The frequency of detectable (mostly low; e.g., 1:5-1:125) anti-exenatide antibody titers at any time during exenatide treatment ranged from 41 to $67 \%$, without clinical significance in terms of effects on glycemic control or adverse events (84-86). Placeboadjusted frequencies of hypoglycemia ranged from 0 to $33 \%$ and were generally lower (not different from placebo) in studies using metformin as background therapy; in one such study, the incidence of hypoglycemic episodes (all mild to moderate) was $5.3 \%$ in patients receiving $10 \mu \mathrm{g}$ exenatide, $4.5 \%$ in those receiving $5 \mu \mathrm{g}$ exenatide, and $5.3 \%$ in those receiving placebo (all twice daily) (84). Severe hypoglycemia was very infrequent, occurring in one patient in one study (86) and no patients in two other studies $(84,85)$. However, when exenatide was used with sulfonylureas, the incidence of hypoglycemia increased with improving glycemic control (i.e., lower $\mathrm{HbA1c}$ and glucose concentrations) (85).

\section{Liraglutide}

As an incretin analog with a $t_{1 / 2}=10-14 \mathrm{~h}$, which is administered once daily, liraglutide is an acylated GLP-1 analog that can bind non-covalently to albumin $(78,90)$.
In a European study of 165 patients with T2D recently reported by Vilsbøll et al. (91), administration of s.c. liraglutide monotherapy once daily (in the evening) for 14 weeks significantly reduced $\mathrm{HbA1}$, FG, and body weight. Absolute changes in $\mathrm{HbA} 1 \mathrm{c}$ were 0.29 percentage point for placebo, -0.98 percentage point for liraglutide $0.65 \mathrm{mg} /$ day, -1.40 percentage points for liraglutide $1.25 \mathrm{mg} /$ day, and -1.45 percentage points for liraglutide $1.90 \mathrm{mg} /$ day (each $P<0.0001$ versus placebo), $+0.3 \%$ for placebo, $-1.0 \%$ for liraglutide $0.65 \mathrm{mg} /$ day, $-1.4 \%$ for liraglutide $1.25 \mathrm{mg} /$ day, and $-1.4 \%$ for liraglutide $1.90 \mathrm{mg} /$ day (each $P<0.0001$ versus placebo). At each dose of liraglutide, FG decreased significantly compared with placebo $(P<0.0001)$. Treatment with liraglutide at the highest dose also significantly decreased fasting glucagon levels and increased the proportions of patients achieving $\mathrm{HbA} 1 \mathrm{c}<7 \%$ (46\% for $1.90 \mathrm{mg} /$ day versus $5 \%$ for placebo) and 90-min PPG $<$ $10 \mathrm{mmol} / \mathrm{l}(180 \mathrm{mg} / \mathrm{dl}): 46$ to $56 \%$ for the three meals with liraglutide compared with 15 to $23 \%$ with placebo. Liraglutide treatment at each dose was associated with a decrease in body weight, which achieved statistical significance (versus placebo) in the $1.90 \mathrm{mg}$ /day treatment arm: $-1.2 \mathrm{~kg}(P<0.04)$. Finally, treatment using each dose of liraglutide was associated with significant declines in the proinsulin:insulin ratio. In a previous active comparator study, adjunctive treatment using liraglutide, titrated from 0.5 to $2.0 \mathrm{mg} /$ day over 5 weeks, in tandem with metformin $1000 \mathrm{mg}$ twice daily significantly reduced FG by $3.9 \mathrm{mmol} / \mathrm{l}(70 \mathrm{mg} / \mathrm{dl}$; $P<0.05)$ and $\mathrm{HbA1c}$ by $0.8 \%(P<0.05)$ compared with metformin monotherapy and significantly lowered FG by $1.2 \mathrm{mmol} / \mathrm{l}(22 \mathrm{mg} / \mathrm{dl} ; P<0.05)$ and body weight by $2.9 \mathrm{~kg}(P<0.05$ compared with metformin together with a sulfonylurea) (74).

As with exenatide, GI symptoms (e.g., nausea, diarrhea) were the chief adverse effects and led to discontinuation in $\sim 3 \%$ of liraglutide patients in the recent European study (91). No patient experienced hypoglycemic episodes (major or minor), and there was no treatment-related anti-liraglutide antibody induction (91). Treatment-related induction of antiliraglutide antibodies has not been observed in liraglutide studies to date $(74,91)$.

\section{Albugon}

Albugon, a recombinant human peptide-albumin derivative containing an analog of GLP-1 that resists the enzymatic activity of DPP-4, improves insulin secretion, and reduces blood glucose in vivo (80). Unlike the 30- to 40-amino acid incretin mimetics exenatide and liraglutide, albugon has less potent anorectic effects in animal studies, although it is not clear if the disparity is secondary to the blood-brain barrier's permeability to the smaller molecules but not to albugon (80). Neither liraglutide nor albugon has been evaluated in direct, active comparator insulin clinical trials. 


\section{Incretin mimetics or insulin for patients with T2D inadequately controlled using oral therapies}

\section{Exenatide versus insulin active comparator studies}

Three published multicenter randomized studies compared 5-10 $\mu$ g exenatide twice daily with insulin in patients with longstanding ( $>6$ years since diagnosis) suboptimally controlled T2D using OHAs at stable doses: metformin and sulfonylureas in studies 1 and 3 below and metformin or sulfonylureas in study 2 :

1) a 26-week open-label parallel-group trial involving 551 patients randomized to exenatide $(n=282$, mean age $=59.8$ years, $\mathrm{HbA} 1 \mathrm{c}=8.2 \%$, and $\mathrm{BMI}=$ $\left.31.4 \mathrm{~kg} / \mathrm{m}^{2}\right)$ or insulin glargine $(n=267$, mean age $=58.0$ years, mean $\mathrm{HbAlc}=8.3 \%$, and mean $\mathrm{BMI}=31.3 \mathrm{~kg} / \mathrm{m}^{2}$ ) titrated by patients using a fixeddose algorithm aiming to achieve a target $\mathrm{FG} \leq 5.5 \mathrm{mmol} / \mathrm{l}(100 \mathrm{mg} / \mathrm{dl}$; not necessarily achieved in all subjects) (92)

2) a 16-week open-label crossover non-inferiority study (93) involving 138 patients (intent-to-treat (ITT) population; mean age $=55$ years, $\mathrm{HbAlc}=9.0 \%$, and $\mathrm{BMI}=31 \mathrm{~kg} / \mathrm{m}^{2}$ ) treated with either exenatide or insulin glargine for 16 weeks with weekly dose adjustments using a forced-titration algorithm (14) aiming to achieve a target $\mathrm{FG} \leq 5.5 \mathrm{mmol} / \mathrm{l}$ (100 mg/dl; not necessarily achieved in all subjects)

3) a 52-week open-label parallel-group non-inferiority study involving 501 patients randomized to exenatide $(n=253$, mean age $=59$ years, $\mathrm{HbAlc}=8.6 \%$, and mean BMI $=30.6 \mathrm{~kg} / \mathrm{m}^{2}$ ) or premixed biphasic insulin aspart (30/70), with the recommendation to titrate to acceptable glycemic control but without a forcedtitration algorithm in 248 patients (mean age $=58$ years, $\mathrm{HbAlc}=8.6 \%$, and $\mathrm{BMI}=30.2 \mathrm{~kg} / \mathrm{m}^{2}$ ), each of which was administered before the morning and evening meals (94).

In these trials, patients were required to have stable body weights (not varying by $>10 \%$ ) for $\geq 3$ months before screening, $\mathrm{HbA} 1 \mathrm{c}$ ranging from 7.0 to $11.0 \%$ at the time of screening (upper limit: $10 \%$ in one study (92)), BMI ranging from 25 to $45 \mathrm{~kg} / \mathrm{m}^{2}\left(40 \mathrm{~kg} / \mathrm{m}^{2}\right.$ in one study (93)) at screening, as well as $\leq 3$ episodes of severe hypoglycemia within 6 months before screening. Exclusion criteria included the use of insulin, thiazolidinediones, $\alpha$-glucosidase inhibitors, meglitinides, or weight loss medications within the prior 3-6 months.

\section{Overview of efficacy}

Exenatide versus insulin glargine studies In the parallel-group study (92), HbA1c decreased significantly from baseline with each treatment (by 1.1\%), and proportions of patients achieving $\mathrm{HbA} 1 \mathrm{c} \leq 7.0 \%$ at treatment week 26 were also similar in the two treatment groups: $46 \%$ (exenatide) and 48\% (insulin). However, body weight progressively declined through treatment week $26(-2.3 \mathrm{~kg} ;-2.6 \%)$ in the exenatide group while progressively increasing $(+1.8 \mathrm{~kg} ;+2.0 \% ; P<0.05$ between-group) in the insulin group. Weight reduction tended to be more marked in patients experiencing nausea or vomiting (versus none) and/or longer durations of nausea on exenatide, but significant weight loss $(-1.9 \mathrm{~kg} ;-2.2 \%)$ occurred even in patients reporting no episodes of nausea $(92,93)$.

Both treatments significantly lowered blood glucose, but the decrease in FG was significantly greater in patients receiving insulin $(-2.9 \mathrm{mmol} / \mathrm{l} ;-52 \mathrm{mg} / \mathrm{dl})$ compared with exenatide $(-1.4 \mathrm{mmol} / \mathrm{l} ;-25 \mathrm{mg} / \mathrm{dl})$, as was the proportion of patients achieving a FG value $<5.5 \mathrm{mmol} / \mathrm{l}(100 \mathrm{mg} / \mathrm{dl}) ; 21.6 \%$ insulin versus $8.6 \%$ exenatide; $P<0.001$. According to self-monitored blood glucose (SMBG) profiles, the mean daily blood glucose values were similar in the exenatide $(8.1 \mathrm{mmol} / \mathrm{l}$, $146 \mathrm{mg} / \mathrm{dl})$ and insulin $(8.0 \mathrm{mmol} / \mathrm{l}, 144 \mathrm{mg} / \mathrm{dl}$; $P>0.05)$ groups. However, patients receiving exenatide had significantly lower PPG excursions. On the other hand, fasting, premeal, and $0300 \mathrm{~h}$ glucose values were significantly lower in the insulin glargine group (92).

In the open-label crossover non-inferiority study (93), with results evaluated for the ITT population, both treatments lowered $\mathrm{HbA} 1 \mathrm{c}$ significantly from baseline, by $1.4 \%(P=0.92$ between-treatments). Based on a $0.01 \%$ between-treatment group difference, exenatide was confirmed to be non-inferior to insulin glargine, in that the upper limit of the 95\% confidence interval was below the a priori margin of $0.4 \%$. Similar proportions of patients achieved $\mathrm{HbA1c} \leq 7 \%$ with each treatment: exenatide (38\%) and insulin glargine (40\%). However, a higher proportion of patients in the exenatide group $(22 \%)$ achieved the treatment target $(95)$ of HbA1c $<$ $6.5 \%$ compared with insulin glargine $(14 \% ; P=0.056)$. While receiving exenatide, patients experienced significant weight loss $(-1.6 \mathrm{~kg})$ compared with a mild weight gain on insulin glargine (least-square mean difference $=-2.2 \mathrm{~kg}$ ). Two-hour PPG excursions were significantly attenuated with exenatide (versus insulin glargine), whereas mean FG values were significantly lower in the insulin group.

On the other hand, replacing insulin treatment with exenatide therapy in patients already receiving insulin does not seem to be advisable, on the basis of findings from a recent pilot study $(96,97)$.

Exenatide versus premixed biphasic insulin In this parallel-group non-inferiority study, both exenatide $(-1.0 \%)$ and premixed biphasic insulin aspart $(-0.9 \%$; $P=0.069$ versus exenatide) significantly lowered $\mathrm{HbA} 1 \mathrm{c}$ from baseline to treatment week 52, with more marked 
effects of exenatide on PPG and biphasic insulin aspart on preprandial glucose (94). A significantly higher proportion of exenatide patients $(18.3 \%)$ achieved $\mathrm{HbA} 1 \mathrm{c}<$ $6.5 \%$ compared with the insulin group $(8.6 \%$; $P=0.0022)$. Paralleling findings from the previous exenatide-insulin comparative study (92), body weight declined progressively with exenatide and increased with insulin. The mean change from baseline to week 52 in body weight was $-2.5 \mathrm{~kg}(-2.9 \%)$ in the exenatide group and $+2.9 \mathrm{~kg}(+3.5 \%)$ in the biphasic insulin aspart group $(P<0.001)$, and the between-treatment disparity was significant at each visit (94). Consistent with the study reported by Heine et al. (92), both treatments reduced fasting serum glucose measurements from baseline to endpoint. According to SMBG profile data, both treatments reduced FG and PPG at each time point, with exenatide being generally superior to insulin in lowering PPG and insulin being generally superior to exenatide in lowering FG. At treatment week 52, patients receiving insulin had significantly $(P<0.04)$ lower preprandial glucose levels, whereas patients receiving exenatide had significantly $(P<0.002)$ lower PPG excursions and/or percent reductions in PPG excursions (94).

In a recent systematic review and meta-analysis, the weighted mean difference in body weight with exenatide (versus insulin) was $-4.8 \mathrm{~kg}(95 \% \mathrm{CI}=-6.0$ to -3.5$)$, whereas weighted mean differences in the proportions of patients achieving $\mathrm{HbAlc}<7 \%$ were not significant between the exenatide and insulin groups (26).

Overview of adverse events/tolerability As in studies in which exenatide was compared with OHAs and/or placebo, exenatide use in the insulin comparator studies was associated with GI-related symptoms as the leading adverse events. These included mild or moderate transient nausea, which occurred in $>50 \%$ of patients in one study (92) and $43 \%$ in another (93), as well as vomiting, diarrhea, abdominal pain, and/or anorexia/ decreased appetite. In the crossover non-inferiority study, 9.6\% of patients reported vomiting on exenatide compared with $3.1 \%$ on insulin glargine (93). GI effects led $<6 \%$ of patients to discontinue treatment $(92,94)$. In the recent systematic review and meta-analysis, the risk ratio of nausea in patients receiving exenatide compared with all comparators (including insulin, OHAs, and placebo) was $3.2(95 \% \mathrm{CI}=2.2-4.6)$, vomiting $3.5(95 \% \mathrm{CI}=2.6-4.7)$, and diarrhea $2.3(95 \% \mathrm{CI}=1.8-2.9)$ (26). Among individuals in the exenatide groups within the two parallel-group insulin comparator studies, frequencies of severe nausea $(4.6 \%)$, discontinuations because of adverse events (9.6\%), and discontinuations because of GI adverse events $(5.1 \%)$ were higher than in the insulin groups $(<1.0 \%$ for each) $(92,94)$.
Based on the recent systematic review and metaanalysis (35), the risk ratio for hypoglycemia was $\sim 1.0$ in patients randomized to exenatide or insulin in the parallelgroup comparator studies (relative risk $(\mathrm{RR})=1.0$; $95 \%$ $\mathrm{CI}=0.5-2.3)(26,92,94)$. Overall incidences of hypoglycemia were similar in the exenatide (7.3 events/patientyear) and insulin glargine (6.3 events/patient-year; $P>0.05$ ) treatment arms in the earlier study (92), as well as in the exenatide (4.7 events/patient-year) and biphasic insulin aspart (5.6 events/patient-year) arms in the latter study (94). In the crossover non-inferiority study, the overall incidences of hypoglycemia were $\sim 15 \%$ in patients on exenatide compared with $25 \%$ on insulin glargine treatment (93). In the exenatide/insulin glargine parallel-group comparative study, four patients in each treatment group (1.4 to $1.5 \%$ ) reported severe hypoglycemia, but none of these episodes required medical treatment or led to treatment withdrawal (92). In the exenatide/insulin open-label glargine crossover noninferiority study, three patients $(\sim 4 \%)$ reported eight episodes of severe hypoglycemia on insulin glargine without treatment discontinuation or dose reduction), while no patient experienced severe hypoglycemia on exenatide treatment (93). In the exenatide/biphasic insulin aspart comparative study, no patients receiving exenatide or insulin reported severe hypoglycemia (94).

The risk of hypoglycemia with exenatide seemed to be largely a function of background OHA treatment. That is, co-administration of exenatide with OHAs not associated with hypoglycemia does not seem to increase the risk of this adverse effect. When sulfonylurea doses were reduced, the incidence of hypoglycemia decreased from 26.9 to 6.1 events/patient-year in the exenatidebiphasic insulin aspart comparator study (94). In the crossover insulin glargine comparator study, incidences of hypoglycemia were similar in patients receiving adjunctive sulfonylureas with exenatide or insulin glargine ( $30 \%$ versus $35 \%$, respectively), which were in turn higher than values for patients receiving adjunctive metformin with either treatment (exenatide + metformin $3 \%$ versus insulin glargine + metformin $17 \% ; P=0.01$ ) (93). Frequencies of anti-exenatide antibodies ranged from $43 \%(92)$ to $45 \%(94)$ in the two parallel-group exenatide-insulin comparator studies.

In 2006, a case of acute pancreatitis was reported in a patient with T2D, who was receiving treatment with exenatide and neutral protamine Hagedorn insulin (98). Recently, the US Food and Drug Administration reviewed 30 post-marketing reports of acute pancreatitis in patients taking exenatide. An association between exenatide and acute pancreatitis has been suspected in some of these cases (99); however, it is not clear that the incidence of acute pancreatitis in patients with T2D receiving exenatide is higher than expected in the overall population of such patients. Following these reports, US manufacturer labeling was updated to include the following precaution: 'Postmarketing cases of acute pancreatitis have been reported. Patients should be 
informed that persistent severe abdominal pain, which may be accompanied by vomiting, is the hallmark symptom of acute pancreatitis. If pancreatitis is suspected (exenatide) and other potentially suspect drugs should be discontinued, confirmatory tests performed and appropriate treatment initiated. Resuming treatment with (exenatide) is not recommended if pancreatitis is confirmed and an alternative etiology for the pancreatitis has not been identified' (100).

\section{Potential clinical implications, limitations, practical considerations, and future research issues}

\section{Potential clinical implications}

Compared with insulin glargine and biphasic insulin aspart, treatment with exenatide has been associated with similar decreases in $\mathrm{HbA} 1 \mathrm{c}$, in tandem with significant net declines from baseline in body weight, superior control of PPG excursions, and similar risks of hypoglycemia (which were highest in patients receiving concomitant sulfonylureas). In contrast, insulin treatment was associated with better control of FG elevations. The effects of exenatide may be particularly desirable in overweight or obese patients and/or those with relatively modest elevations in $\mathrm{HbA1c}$, in whom PPG elevations account for a greater proportion of HbAlc than FG elevations (whereas the converse is true for those with more marked HbAlc elevations (101)). Obesity can worsen hyperglycemia, dyslipidemia, and/or insulin resistance, as well as increase the risk of hypertension, other forms of cardiovascular disease, and non-alcoholic fatty liver disease (102-106).

Mechanisms linking obesity (and central adiposity) with cardiovascular disease and mortality, including endothelial dysfunction and atherosclerosis secondary to dyslipidemia, hypertension, inflammation, and changes in the coagulation-fibrinolysis cascades, are also becoming increasingly evident (22). Improved weight management is an important treatment objective for most obese T2D patients (103). For an average loss of $5 \%$ of body weight in overweight individuals, $\mathrm{HbA1c}$ is expected to decline by $0.6 \%$, and the need for hypoglycemic agents may also decrease (102).

Also promising on a more conceptual level is the finding of exenatide's and liraglutide's beneficial effects on indices of $\beta$-cell secretory function (or dysfunction). However, such effects were not assessed in all studies, and their durability is not clear.

\section{Potential limitations}

As with many studies of antidiabetic treatments, incretin mimetics and insulin were evaluated according to their effects on surrogate endpoints (e.g., HbA1c, FG, and PPG), not clinical events. In addition to the relatively short-term nature of the insulin comparator studies, the metabolic and other effects of exenatide have not been compared with a more nearly physiologic basal-bolus approach, which might include insulin glargine (basal component) plus a rapid-acting insulin (regular insulin or analogs, bolus or prandial component). It has also been argued that the exenatide-biphasic insulin aspart study, which did not have a forced-titration design, did not fully optimize the insulin dose, and that neither exenatide-insulin parallelgroup comparator study achieved a level of glycemic regulation at endpoint comparable with that achieved using insulin glargine or other insulin formulations (14, 107-109); however, this conclusion is somewhat controversial $(13,110-112)$, in part because of variation in baseline HbA1c and sulfonylurea use across studies.

In the exenatide-biphasic insulin aspart comparator study (94), physicians were encouraged to target both FG and PPG to attain an optimal balance between HbA1c lowering and hypoglycemic risk. In the absence of a strict dose titration schedule such as the one employed by Riddle et al. in the treat-to-target trial (14), it is conceivable that physicians in the exenatide comparator study used a conservative approach when administering biphasic insulin aspart to avert hypoglycemia (versus achieving optimal glycemic control), resulting in lower than optimal insulin doses $(94,110)$. On the other hand, the use of exenatide and premixed insulin in this study should have closely reflected their real-world use.

Other potential limitations of the exenatide-insulin comparator studies center on the eligibility criteria and sociodemographic and clinical characteristics of the patient populations. These included stable body weight and an absence of recent treatments with OHAs or weightreducing agents. Mean ages in the insulin comparator studies were below 60 years, and patients of African descent may have been somewhat under-represented.

\section{Practical considerations}

On the basis of findings considered in the present review and elsewhere, exenatide therapy can be considered as an alternative to insulin in patients with treatment failure on metformin monotherapy or on metformin together with a sulfonylurea. In the United States and Europe, exenatide is indicated as a treatment adjunct to enhance glycemic regulation in patients with $\mathrm{T} 2 \mathrm{D}$, who are receiving an $\mathrm{OHA}$ or a combination of $\mathrm{OHAs}$ $(100,113)$. Potential patient factors that are consistent or inconsistent with the use of incretin mimetics or insulin are presented in Table 1.

\section{Future research issues}

The durability of treatment effects on surrogate variables (e.g., HbA1c, PPG, body weight, and $\beta$-cell secretory function) should be further evaluated in longer term studies involving larger and more heterogeneous patient populations. For instance, it might be of interest to evaluate the use of incretin mimetics as alternatives to OHAs or 
Table 1 Factors more consistent with the use of the incretin mimetic exenatide ${ }^{a}$ rather than insulin (and vice versa) ${ }^{b}$.

Factors more consistent with treatment using the incretin mimetic exenatide and/or inconsistent with treatment using insulin

$\mathrm{HbA1c}<1.5$ percentage point above target

Relatively well-controlled FG concentration

Primarily PPG concentration peaks

Need to avoid hypoglycemia (caveat: concomitant medications)

Failure of measures to control body weight

No clinical signs of catabolism

Patient needs treatment that is simple in execution (no dose titration, timing of injection relative to meals not critical)

Patient has little control over (varying) meal sizes, carbohydrate content

Patient does not want to perform blood glucose monitoring
Factors consistent with treatment using insulin and/or inconsistent with treatment using the incretin mimetic exenatide

$\mathrm{HbA1c} \geq 1.5$ percentage point above target

High FG concentration

Relatively small PPG concentration peaks

No problems associated with hypoglycemia

Some prior success of measures to control body weight

Clinical signs of catabolism

Patient is willing and able to execute a more complicated treatment regimen (dose titration, exact timing of injection relative to meals not critical)

Patient has good control over (varying) meal sizes

Patient is willing to perform blood glucose monitoring

${ }^{a}$ At this writing, the effects of treatment with other incretin mimetics (e.g., liraglutide) have not been compared directly with those of insulin treatment

${ }^{b}$ These patient-related factors may need to be considered when oral hypoglycemic agents fail to achieve adequate glycemic control and a decision must be made between incretin mimetics and insulin.

insulin in patients with different stages of disease and residual $\beta$-cell function. Also of possible interest are studies to further characterize the effects of incretin mimetics on body composition, particularly central adiposity, and determine whether other potential benefits of incretin mimetics (e.g., on blood pressure) are related to, or independent of, changes in body weight. Studies comparing liraglutide, albugon, or other incretin mimetics with insulin might also be useful. Finally, although data suggest that anti-exenatide antibodies have very little impact on safety and other study outcomes (75-77), continued pharmacovigilance for antigenicity is warranted.

\section{Conclusions}

Treatment of T2D often escalates from lifestyle modifications to OHA regimens to insulin, but insulin treatment has potential limitations such as inadequate control of PPG excursions, weight gain, and hypoglycemia. Incretins, including GLP-1, help to maintain glucose homeostasis through effects on islet $\alpha$ - and $\beta$-cells and stimulate insulin secretion in a glucose-dependent manner. Treatment with incretin mimetics is associated with enhanced glycemic regulation (including reduced PPG excursions), concomitant reductions in (or neutral effects on) body weight, and a low risk of hypoglycemia. On the other hand, treatment with insulin appears to be more effective in lowering FG levels. When oral agents have failed to maintain adequate glycemic control, incretin mimetics may be particularly well suited to the treatment of patients who are overweight or obese, have relatively well-controlled FG with primarily PPG peaks, HbAlc within 1.5 percentage point of target, little control over meal sizes and carbohydrate contents, and prefer simple treatment without the need for glucose monitoring. However, insulin treatment may be better suited to patients with less well-controlled FG levels and small PPG peaks, HbAlc at least 1.5 percentage point above target, control over meal sizes, and willingness to execute a more complicated treatment regimen and perform blood glucose monitoring. Incretin mimetics may help to expand the T2D clinical paradigm, more meaningfully realize Unger's 'bihormonal hypothesis' (28), and enable more effective treatment of a broader spectrum of patients.

\section{Acknowledgements}

Financial disclosures: This review was supported by Amylin Pharmaceuticals/Eli Lilly. L F Van Gaal has received research grants from Fonds Wetenschappelijk Onderzoek Vlaanderen (Belgium); is on the speakers' bureau for Abbott Pharma, AstraZeneca, Eli Lilly, and Sanofi-Aventis; and is a member of advisory boards for Abbott Pharma, Amylin Pharmaceuticals/Eli Lilly, Johnson \& Johnson, Roche, and Sanofi-Aventis. No honorarium was offered to, or received by, Dr Van Gaal for writing the present review article. S W Gutkin is a consultant to Eli Lilly and Merck. He was offered and received an honorarium from Eli Lilly for providing editorial support in writing the present review article. M A Nauck has received lecture fees, grant support, or consultant honoraria from pharmaceutical companies involved in the development of incretin mimetics (Amylin Pharmaceuticals/Eli Lilly, NovoNordisk, GlaxoSmithKline, ConjuChem, Sanofi-Aventis) and dipeptidyl peptidase 4 inhibitors (Merck, Sharp \& Dohme, Novartis, Probiodrugs, AstraZeneca, Bristol-Myers Squibb). No honorarium was offered to, or received by, Dr Nauck for writing the present review article.

\section{References}

1 International Diabetes Federation. Diabetes Atlas Brussels: International Diabetes Federation, 2006.

2 Del Prato S \& Marchetti P. Beta- and alpha-cell dysfunction in type 2 diabetes. Hormone and Metabolic Research 200436 775-781. 
3 UK Prospective Diabetes Study Group. UK prospective diabetes study 16. Overview of 6 years' therapy of type II diabetes: a progressive disease. Diabetes 199544 1249-1258.

4 Khaw KT, Wareham N, Bingham S, Luben R, Welch A \& Day N. Association of hemoglobin A1c with cardiovascular disease and mortality in adults: the European prospective investigation into cancer in Norfolk. Annals of Internal Medicine $2004141413-420$.

5 Stratton IM, Adler AI, Neil HA, Matthews DR, Manley SE, Cull CA, Hadden D, Turner RC \& Holman RR. Association of glycaemia with macrovascular and microvascular complications of type 2 diabetes (UKPDS 35): prospective observational study. BMJ $2000 \mathbf{3 2 1}$ 405-412.

6 The Diabetes Control and Complications Trial Research Group. The absence of a glycemic threshold for the development of long-term complications: the perspective of the diabetes control and complications trial. Diabetes 199645 1289-1298.

7 Malmberg K. Prospective randomised study of intensive insulin treatment on long term survival after acute myocardial infarction in patients with diabetes mellitus. DIGAMI (diabetes mellitus, insulin glucose infusion in acute myocardial infarction) Study Group. BMJ $19973141512-1515$.

8 Coutinho M, Gerstein HC, Wang Y \& Yusuf S. The relationship between glucose and incident cardiovascular events. A metaregression analysis of published data from 20 studies of 95783 individuals followed for 12.4 years. Diabetes Care 199922 233-240.

9 Butler AE, Janson J, Bonner-Weir S, Ritzel R, Rizza RA \& Butler PC. Beta-cell deficit and increased beta-cell apoptosis in humans with type 2 diabetes. Diabetes 200352 102-110.

10 Turner RC, Cull CA, Frighi V \& Holman RR. Glycemic control with diet, sulfonylurea, metformin, or insulin in patients with type 2 diabetes mellitus: progressive requirement for multiple therapies (UKPDS 49). UK Prospective Diabetes Study (UKPDS) Group. Journal of the American Medical Association $19992812005-2012$.

11 Van Gaal LF \& De LI. Rationale and options for combination therapy in the treatment of type 2 diabetes. Diabetologia $2003 \mathbf{4 6}$ M44-M50.

12 Raskin P, Allen E, Hollander P, Lewin A, Gabbay RA, Hu P, Bode B, Garber A \& INITIATE Study Group. Initiating insulin therapy in type 2 diabetes: a comparison of biphasic and basal insulin analogs. Diabetes Care 200528 260-265.

13 Rosenstock J, Dailey G, Massi-Benedetti M, Fritsche A, Lin Z \& Salzman A. Reduced hypoglycemia risk with insulin glargine: a meta-analysis comparing insulin glargine with human NPH insulin in type 2 diabetes. Diabetes Care 200528 950-955.

14 Riddle MC, Rosenstock J \& Gerich J. The treat-to-target trial: randomized addition of glargine or human NPH insulin to oral therapy of type 2 diabetic patients. Diabetes Care 200326 3080-3086.

15 Fritsche A, Schweitzer MA \& Haring HU. Glimepiride combined with morning insulin glargine, bedtime neutral protamine hagedorn insulin, or bedtime insulin glargine in patients with type 2 diabetes. A randomized, controlled trial. Annals of Internal Medicine 2003138 952-959.

16 Yki-Jarvinen H, Dressler A \& Ziemen M. Less nocturnal hypoglycemia and better post- dinner glucose control with bedtime insulin glargine compared with bedtime NPH insulin during insulin combination therapy in type 2 diabetes. HOE 901/3002 Study Group. Diabetes Care 200023 1130-1136.

17 Cryer PE. Hypoglycemia is the limiting factor in the management of diabetes. Diabetes/Metabolism Research and Reviews 199915 42-46.

18 Davis S \& Alonso MD. Hypoglycemia as a barrier to glycemic control. Journal of Diabetes and its Complications 200418 60-68.

19 Lundkvist J, Berne C, Bolinder B \& Jönsson L. The economic and quality of life impact of hypoglycemia. European Journal of Health Economics 20056 197-202.

20 Bonora E, Targher G, Formentini G, Calcaterra F, Lombardi S, Marini F, Zenari L, Saggiani F, Poli M, Perbellini S, Raffaelli A, Gemma L, Santi L, Bonadonna RC \& Muggeo M. The metabolic syndrome is an independent predictor of cardiovascular disease in type 2 diabetic subjects. Prospective data from the Verona Diabetes Complications Study. Diabetic Medicine 200421 52-58.

21 Hillier TA \& Pedula KL. Characteristics of an adult population with newly diagnosed type 2 diabetes: the relation of obesity and age of onset. Diabetes Care 200124 1522-1527.

22 Van Gaal LF, Mertens IL \& De Block CE. Mechanisms linking obesity with cardiovascular disease. Nature $2006 \mathbf{4 4 4} 875-880$.

23 Klein S, Sheard NF, Pi-Sunyer X, Daly A, Wylie-Rosett J, Kulkarni K, Clark NG, American Diabetes Association, North American Association for the Study of Obesity \& American Society for Clinical Nutrition. Weight management through lifestyle modification for the prevention and management of type 2 diabetes: rationale and strategies: a statement of the American Diabetes Association, the North American Association for the Study of Obesity, and the American Society for Clinical Nutrition. Diabetes Care 200427 2067-2073.

24 Kerr D \& Cavan D. Treating obese patients with poorly controlled diabetes: confessions of an insulin therapist. Diabetes/Metabolism Research and Reviews 199915 219-225.

25 Adams KF, Schatzkin A, Harris TB, Kipnis V, Mouw T, BallardBarbash R, Hollenbeck A \& Leitzmann MF. Overweight, obesity, and mortality in a large prospective cohort of persons 50 to 71 years old. New England Journal of Medicine $2006355763-778$.

26 Amori RE, Lau J \& Pittas AG. Efficacy and safety of incretin therapy in type 2 diabetes: systematic review and meta-analysis. Journal of the American Medical Association 2007298 194-206.

27 Ovalle F \& Bell DS. Effect of rosiglitazone versus insulin on the pancreatic beta-cell function of subjects with type 2 diabetes. Diabetes Care 200427 2585-2589.

28 Unger RH \& Orci L. The essential role of glucagon in the pathogenesis of diabetes mellitus. Lancet 1975 1 14-16.

29 Porte D Jr \& Kahn SE. The key role of islet dysfunction in type II diabetes mellitus. Clinical and Investigative Medicine 199518 247-254.

30 Zander M, Madsbad S, Madsen JL \& Holst JJ. Effect of 6-week course of glucagon-like peptide 1 on glycaemic control, insulin sensitivity, and beta-cell function in type 2 diabetes: a parallel-group study. Lancet $2002359824-830$.

31 Toft-Nielsen MB, Madsbad S \& Holst JJ. Continuous subcutaneous infusion of glucagon-like peptide 1 lowers plasma glucose and reduces appetite in type 2 diabetic patients. Diabetes Care 199922 1137-1143.

32 Wang Y, Perfetti R, Greig NH, Holloway HW, DeOre KA, MontroseRafizadeh C, Elahi D \& Egan JM. Glucagon-like peptide-1 can reverse the age-related decline in glucose tolerance in rats. Journal of Clinical Investigation 199799 2883-2889.

33 Willms B, Werner J, Holst JJ, Orskov C, Creutzfeldt W \& Nauck MA. Gastric emptying, glucose responses, and insulin secretion after a liquid test meal: effects of exogenous glucagon-like peptide-1 (GLP-1)-(7-36) amide in type 2 (noninsulin-dependent) diabetic patients. Journal of Clinical Endocrinology and Metabolism 1996 $81327-332$.

34 Nauck MA, Kleine N, Orskov C, Holst JJ, Willms B \& Creutzfeldt W. Normalization of fasting hyperglycaemia by exogenous glucagonlike peptide 1 (7-36 amide) in type 2 (non-insulin-dependent) diabetic patients. Diabetologia 199336 741-744.

35 Bregenholt S, Moldrup A, Blume N, Karisen AE, NissenFriedrichsen B, Tornhave D, Knudsen LB \& Petersen JS. The long-acting glucagon-like peptide-1 analogue, liraglutide, inhibits beta-cell apoptosis in vitro. Biochemical and Biophysical Research Communications 2005330 577-584.

$36 \mathrm{Xu} \mathrm{G}$, Stoffers DA, Habener JF \& Bonner-Weir S. Exendin- 4 stimulates both beta-cell replication and neogenesis, resulting in increased beta-cell mass and improved glucose tolerance in diabetic rats. Diabetes $1999 \mathbf{4 8} 2270-2276$.

37 Drucker DJ. Dipeptidyl peptidase- 4 inhibition and the treatment of type 2 diabetes: preclinical biology and mechanisms of action. Diabetes Care 200730 1335-1343.

38 Åhren B. Dipeptidyl peptidase- 4 inhibitors: clinical data and clinical implications. Diabetes Care 200730 1344-1350. 
39 Creutzfeldt W. The incretin concept today. Diabetologia 197916 $75-85$.

40 Elrick H, Stimmler L, Hlad CJ Jr \& Arai Y. Plasma insulin response to oral and intravenous glucose administration. Journal of Clinical Endocrinology and Metabolism 196424 1076-1082.

41 Perley MJ \& Kipnis DM. Plasma insulin responses to oral and intravenous glucose: studies in normal and diabetic subjects. Journal of Clinical Investigation 196746 1954-1962.

42 Orskov C, Rabenhoj L, Wettergren A, Kofod H \& Holst JJ. Tissue and plasma concentrations of amidated and glycine-extended glucagon-like peptide I in humans. Diabetes 199443 535-539.

43 Drucker DJ. Glucagon.com. Available at www glucagon.com. Accessed April 10, 2007.

44 Mortensen K, Christensen LL, Holst JJ \& Orskov C. GLP-1 and GIP are colocalized in a subset of endocrine cells in the small intestine. Regulatory Peptides 2003114 189-196.

45 Mortensen K, Petersen LL \& Orskov C. Colocalization of GLP-1 and GIP in human and porcine intestine. Annals of the New York Academy of Sciences 2000921 469-472.

46 Drucker DJ \& Nauck MA. The incretin system: glucagon-like peptide-1 receptor agonists and dipeptidyl peptidase- 4 inhibitors in type 2 diabetes. Lancet 2006368 1696-1705.

47 Farilla L, Bulotta A, Hirshberg B, Li Calzi S, Khoury N, Noushmehr H, Bertolotto C, Di Mario U, Harlan DM \& Perfetti R. Glucagon-like peptide 1 inhibits cell apoptosis and improves glucose responsiveness of freshly isolated human islets. Endocrinology 2003144 5149-5158.

48 Turton MD, O'Shea D, Gunn I, Beak SA, Edwards CM, Meeran K, Choi SJ, Taylor GM, Heath MM, Lambert PD, Wilding JP, Smith DM, Ghatei MA, Herbert J \& Bloom SR. A role for glucagon-like peptide-1 in the central regulation of feeding. Nature 1996379 69-72.

49 Larsen PJ, Tang-Christensen M, Holst JJ \& Orskov C. Distribution of glucagon-like peptide-1 and other preproglucagon-derived peptides in the rat hypothalamus and brainstem. Neuroscience 199777 257-270.

50 Orskov C, Poulsen SS, Moller M \& Holst JJ. Glucagon-like peptide I receptors in the subfornical organ and the area postrema are accessible to circulating glucagon-like peptide I. Diabetes 199645 832-835.

51 Kim SJ, Nian C \& McIntosh CH. Resistin is a key mediator of glucose-dependent insulinotropic polypeptide (GIP) stimulation of lipoprotein lipase (LPL) activity in adipocytes. Journal of Biological Chemistry 2007282 34139-34147.

52 Yip RG, Boylan MO, Kieffer TJ \& Wolfe MM. Functional GIP receptors are present on adipocytes. Endocrinology 1998139 4004-4007.

53 Perea A, Clemente F, Martinell J, Villanueva-Penacarrillo ML \& Valverde I. Physiological effect of glucagon in human isolated adipocytes. Hormone and Metabolic Research 199527 372-375.

54 Carranza MC, Simon MA, Torres A, Romero B \& Calle C. Identification of glucagon receptors in human adipocytes from a liposarcoma. Journal of Endocrinological Investigation 199316 439-442.

55 Ruiz-Grande C, Alarcon C, Merida E \& Valverde I. Lipolytic action of glucagon-like peptides in isolated rat adipocytes. Peptides 1992 $1313-16$.

56 Bertrand HA, Masoro EJ \& Yu BP. Maintenance of glucagonpromoted lipolysis in adipocytes by food restriction. Endocrinology 1980107 591-595.

57 Starich GH, Bar RS \& Mazzaferri EL. GIP increases insulin receptor affinity and cellular sensitivity in adipocytes. American Journal of Physiology 1985249 E603-E607.

58 Samols E, Tyler J, Marri G \& Marks V. Stimulation of glucagon secretion by oral glucose. Lancet 19652 1257-1259.

59 Samols E \& Marks V. Interpretation of the intravenous glucose test. Lancet $19651462-463$.

60 Mack CM, Moore CX, Jodka CM, Bhavsar S, Wilson JK, Hoyt JA, Roan JL, Vu C, Laugero KD, Parkes DG \& Young AA. Antiobesity action of peripheral exenatide (exendin-4) in rodents: effects on food intake, body weight, metabolic status and side-effect measures. International Journal of Obesity 200630 1332-1340.

61 Poon T, Nelson P, Shen L, Mihm M, Taylor K, Fineman M \& Kim D. Exenatide improves glycemic control and reduces body weight in subjects with type 2 diabetes: a dose-ranging study. Diabetes Technology \& Therapeutics 20057 467-477.

62 Blonde L, Klein EJ, Han J, Zhang B, Mac SM, Poan TH, Taylor KL, Trautmann ME, Kim DD \& Kendall DM. Interim analysis of the effects of exenatide treatment on A1C, weight and cardiovascular risk factors over 82 weeks in 314 overweight patients with type 2 diabetes. Diabetes, Obesity and Metabolism 20068 436-447.

63 Degn KB, Brock B, Juhl CB, Djurhuus CB, Grubert J, Kim D, Han J, Taylor K, Fineman M \& Schnutz O. Effect of intravenous infusion of exenatide (synthetic exendin-4) on glucose-dependent insulin secretion and counterregulation during hypoglycemia. Diabetes $2004532397-2403$.

64 Gedulin BR, Nikoulina SE, Smith PA, Gedulin G, Nielsen LL, Baron AD, Parkes DG \& Young AA. Exenatide (exendin-4) improves insulin sensitivity and $\beta$-cell mass in insulin-resistant obese fa/fa Zucker rats independent of glycemia and body weight. Endocrinology 2005146 2069-2076.

65 Gedulin BR, Smith P, Prickett KS, Tryon M, Barnhill S, Reynolds J, Nielsen LL, Parkes DG \& Young AA. Dose-response for glycaemic and metabolic changes 28 days after single injection of long-acting release exenatide in diabetic fatty Zucker rats. Diabetologia 2005 48 1380-1385.

66 Fehse F, Trautmann M, Holst JJ, Halseth AE, Nanayakkara N, Nielsen LL, Fineman MS, Kim DD \& Nauck MA. Exenatide augments first- and second-phase insulin secretion in response to intravenous glucose in subjects with type 2 diabetes. Journal of Clinical Endocrinology and Metabolism 200590 5991-5997.

67 Nielsen LL, Young AA \& Parkes DG. Pharmacology of exenatide (synthetic exendin-4): a potential therapeutic for improved glycemic control of type 2 diabetes. Regulatory Peptides 2004 $11777-88$.

68 Kolterman OG, Buse JB, Fineman MS, Gaines E, Heintz S, Bicsak TA, Taylor K, Kim D, Aisporna M, Wang Y \& Baron AD. Synthetic exendin-4 (exenatide) significantly reduces postprandial and fasting plasma glucose in subjects with type 2 diabetes. Journal of Clinical Endocrinology and Metabolism $2003 \mathbf{8 8}$ 3082-3089.

69 Egan JM, Clocquet AR \& Elahi D. The insulinotropic effect of acute exendin-4 administered to humans: comparison of nondiabetic state to type 2 diabetes. Journal of Clinical Endocrinology and Metabolism 200287 1282-1290.

70 Parkes DG, Pittner R, Jodka C, Smith P \& Young A. Insulinotropic actions of exendin- 4 and glucagon-like peptide- 1 in vivo and in vitro. Metabolism $2001 \mathbf{5 0} 583-589$.

71 Szayna M, Doyle ME, Betkey JA, Holloway HW, Spencer RG, Greig NH \& Egan JM. Exendin- 4 decelerates food intake, weight gain, and fat deposition in Zucker rats. Endocrinology 2000141 1936-1941.

72 Young AA, Gedulin BR, Bhavsar S, Bodkin N, Jodka C, Hansen B \& Denaro M. Glucose-lowering and insulin-sensitizing actions of exendin-4: studies in obese diabetic (ob/ob, db/db) mice, diabetic fatty Zucker rats, and diabetic rhesus monkeys (Macaca mulatta). Diabetes 199948 1026-1034.

73 Vilsbøll T, Zdravkovic M, Le-Thi T, Krarup T, Schmitz O, Courrèges JP, Verhoeven R, Bugánová I \& Madsbad S. Liraglutide significantly improves glycemic control and lowers body weight without risk of either major or minor hypoglycemic episodes in subjects with type 2 diabetes (abstract 115-OR). Diabetes 200655 27-28.

74 Nauck MA, Hompesch M, Filipczak R, Le TD, Zdravkovic M \& Gumprecht J. Five weeks of treatment with the GLP-1 analogue liraglutide improves glycaemic control and lowers body weight in subjects with type 2 diabetes. Experimental and Clinical Endocrinology and Diabetes $2006 \mathbf{1 1 4} 417-423$.

75 Madsbad S, Schmitz O, Ranstam J, Jakobsen G \& Matthews DR. Improved glycemic control with no weight increase in patients 
with type 2 diabetes after once-daily treatment with the longacting glucagon-like peptide 1 analog liraglutide (NN2211): a 12-week, double-blind, randomized, controlled trial. Diabetes Care 200427 1335-1342.

76 Bjerre Knudsen L, Moller Knudsen S \& Wilken M. Plasma protein binding of NN2211, a long-acting derivative of GLP-1, is important for its efficacy (abstract). Diabetes 200552 321-322.

77 Saad M, An B \& Santiago O. The effect of NN2211, a long-acting GLP-1 derivative, on glycemic control and body weight in obese patients with type 2 diabetes (abstract). Diabetologia 20024544 .

78 Elbrond B, Jakobsen G, Larsen S, Agersø H, Jensen LB, Rolan P, Sturis J, Hatorp V \& Zdravkovic M. Pharmacokinetics, pharmacodynamics, safety, and tolerability of a single-dose of NN2211, a long-acting glucagon-like peptide 1 derivative, in healthy male subjects. Diabetes Care 200225 1398-1404.

79 Kim JG, Baggio LL, Bridon DP, Castaigne JP, Robitaille MF, Jetté L, Benquet C \& Drucker DJ. Development and characterization of a glucagon-like peptide 1-albumin conjugate: the ability to activate the glucagon-like peptide 1 receptor in vivo. Diabetes 200352 751-759.

80 Baggio LL, Huang Q, Brown TJ \& Drucker DJ. A recombinant human glucagon-like peptide (GLP)-1-albumin protein (albugon) mimics peptidergic activation of GLP-1 receptor-dependent pathways coupled with satiety, gastrointestinal motility, and glucose homeostasis. Diabetes 200453 2492-2500.

81 Eng J, Kleinman WA, Singh L, Singh G \& Raufman JP. Isolation and characterization of exendin-4, an exendin-3 analogue, from Heloderma suspectum venom. Further evidence for an exendin receptor on dispersed acini from guinea pig pancreas. Journal of Biological Chemistry 1992267 7402-7405.

82 Kolterman OG, Kim DD, Shen L, Ruggles JA, Nielsen LL, Fineman MS \& Baron AD. Pharmacokinetics, pharmacodynamics, and safety of exenatide in patients with type 2 diabetes mellitus. American Journal of Health System Pharmacy 200562 173-181.

83 Nielsen LL \& Baron AD. Pharmacology of exenatide (synthetic exendin-4) for the treatment of type 2 diabetes. Current Opinion in Investigational Drugs 20034 401-405.

84 DeFronzo RA, Ratner RE, Han J, Kim DD, Fineman MS \& Baron AD. Effects of exenatide (exendin-4) on glycemic control and weight over 30 weeks in metformin-treated patients with type 2 diabetes. Diabetes Care 200528 1092-1100.

85 Buse JB, Henry RR, Han J, Kim DD, Fineman MS \& Baron AD. Effects of exenatide (exendin-4) on glycemic control over 30 weeks in sulfonylurea-treated patients with type 2 diabetes. Diabetes Care $2004272628-2635$.

86 Kendall DM, Riddle MC, Rosenstock J, Zhuang D, Kim DD, Fineman MS \& Baron AD. Effects of exenatide (exendin-4) on glycemic control over 30 weeks in patients with type 2 diabetes treated with metformin and a sulfonylurea. Diabetes Care $2005 \mathbf{2 8}$ 1083-1091.

87 Klonoff DC, Buse JB, Nielsen LL, Guan X, Bowlus CL, Holcombe JH, Wintle ME \& Maggs DG. Exenatide effects on diabetes, obesity, cardiovascular risk factors and hepatic biomarkers in patients with type 2 diabetes treated for at least 3 years. Current Medical Research and Opinion 200824 275-286.

88 Buse JB, Klonoff DC, Nielsen LL, Guan X, Bowlus CL, Holcombe JH, Maggs DG \& Wintle ME. Metabolic effects of two years of exenatide treatment on diabetes, obesity, and hepatic biomarkers in patients with type 2 diabetes: an interim analysis of data from the openlabel, uncontrolled extension of three double-blind, placebocontrolled trials. Clinical Therapeutics 200729 139-153.

89 Fineman MS, Shen LZ, Taylor K, Kim DD \& Baron AD. Effectiveness of progressive dose-escalation of exenatide (exendin-4) in reducing dose-limiting side effects in subjects with type 2 diabetes. Diabetes/Metabolism Research and Reviews 200420 411-417.

90 Agerso H, Jensen LB, Elbrond B, Rolan P \& Zdravkovic M. The pharmacokinetics, pharmacodynamics, safety and tolerability of NN2211, a new long-acting GLP-1 derivative, in healthy men. Diabetologia 200245 195-202.

91 Vilsbøll T, Zdravkovic M, Le Thi T, Krarup T, Schmitz O, Courrèges JP, Verhoeven R, Bugánová I \& Madsbad S. Liraglutide, a long-acting human glucagon-like peptide-1 analog, given as monotherapy significantly improves glycemic control and lowers body weight without risk of hypoglycemia in patients with type 2 diabetes. Diabetes Care 200730 1608-1610.

92 Heine RJ, Van Gaal LF, Johns D, Mihm MJ, Widel MH \& Brodows RG. Exenatide versus insulin glargine in patients with suboptimally controlled type 2 diabetes: a randomized trial. Annals of Internal Medicine 2005143 559-569.

93 Barnett AH, Burger J, Johns D, Brodows R, Kendall DM, Roberts A \& Trautmann ME. Tolerability and efficacy of exenatide and titrated insulin glargine in adult patients with type 2 diabetes previously uncontrolled with metformin or a sulfonylurea: a multinational, randomized, open-label, two-period crossover noninferiority trial. Clinical Therapeutics 200729 2333-2348.

94 Nauck MA, Duran S, Kim D, Johns D, Northrup J, Festa A, Brodows R \& Trautmann ME. A comparison of twice-daily exenatide and biphasic insulin aspart in patients with type 2 diabetes who were suboptimally controlled with sulfonylurea and metformin: a non-inferiority study. Diabetologia $2007 \mathbf{5 0}$ 259-267.

95 International Diabetes Federation. Global guidelines for type 2 diabetes: clinical guidelines task force. 2005. Brussels: International Diabetes Federation. Available at www.idf.org Accessed February 28, 2007.

96 Davis SN, Johns D, Maggs D, Xu H, Northrup JH \& Brodows RG. Exploring the substitution of exenatide for insulin in patients with type 2 diabetes treated with insulin in combination with oral antidiabetes agents. Diabetes Care 200730 2767-2772.

97 Rosenstock J \& Fonseca V. Missing the point: substituting exenatide for nonoptimized insulin: going from bad to worse! Diabetes Care 200730 2972-2973.

98 Denker PS \& Dimarco PE. Exenatide (exendin-4)-induced pancreatitis: a case report. Diabetes Care 200629471.

99 Food and Drug Administration Information for Healthcare Professionals Exenatide (marketed as Byetta). Available at www.fda.gov/cder/drug/InfoSheets/HCP/exenatideHCP.htm Accessed January 17, 2008.

100 Eli Lilly/Amylin. Byetta ${ }^{\circledR}$ (exenatide) US prescribing information. Available at http://pi.lilly.com/us/byetta-pi.pdf Accessed January 15, 2008.

101 Monnier L, Lapinski H \& Colette C. Contributions of fasting and postprandial plasma glucose increments to the overall diurnal hyperglycemia of type 2 diabetic patients: variations with increasing levels of $\mathrm{HbA}(1 \mathrm{c})$. Diabetes Care 200326 881-885.

102 Maggio CA \& Pi-Sunyer FX. Obesity and type 2 diabetes. Endocrinology and Metabolism Clinics of North America 200332 805-822 (viii).

103 Anderson JW, Kendall CW \& Jenkins DJ. Importance of weight management in type 2 diabetes: review with meta-analysis of clinical studies. Journal of the American College of Nutrition 200322 331-339.

104 Stein CJ \& Colditz GA. The epidemic of obesity. Journal of Clinical Endocrinology and Metabolism $2004892522-2525$.

105 Yki-Jarvinen $\mathrm{H}$ \& Westerbacka J. The fatty liver and insulin resistance. Current Molecular Medicine 20055 287-295.

106 Bray GA. Medical consequences of obesity. Journal of Clinical Endocrinology and Metabolism 200489 2583-2589.

107 Home PD, Comment on: Nauck MA, Duran S \& Kim D. A comparison of twice-daily exenatide and biphasic insulin aspart in patients with type 2 diabetes who were suboptimally controlled with sulfonylurea and metformin: a non-inferiority study. Diabetologia 2007; 50 1561-1562.

108 Garber AJ, Wahlen J, Wahl T, Bressler P, Braceras R, Allen E \& Jain R. Attainment of glycaemic goals in type 2 diabetes with once-, twice-, or thrice-daily dosing with biphasic insulin aspart 70/30 (The 1-2-3 study). Diabetes, Obesity and Metabolism 20068 $58-66$.

109 Hermansen K, Davies M, Derezinski T, Martinez RG, Clauson P \& Home P. A 26-week, randomized, parallel, treat-to-target trial 
comparing insulin detemir with NPH insulin as add-on therapy to oral glucose-lowering drugs in insulin-naive people with type 2 diabetes. Diabetes Care 200629 1269-1274.

110 Nauck MA, Trautman M, Brodows R, Johns D, Northrup J \& Kim D. Response to comment on: Nauck MA Duran S et al. A comparison of twice-daily exenatide and biphasic insulin aspart in patients with type 2 diabetes who were suboptimally controlled with sulfonylurea and metformin: a non-inferiority study. Diabetologia 2007; 50 1563-1564.

111 Janka HU, Plewe G, Riddle MC, Kliebe-Frisch C, Schweitzer MA \& Yki-Jarvinen H. Comparison of basal insulin added to oral agents versus twice-daily premixed insulin as initial insulin therapy for type 2 diabetes. Diabetes Care 200528 254-259.
112 Boehm BO, Home PD, Behrend C, Kamp NM \& Lindholm A. Premixed insulin aspart 30 vs. premixed human insulin 30/70 twice daily: a randomized trial in type 1 and type 2 diabetic patients. Diabetic Medicine 200219 393-399.

113 Eli Lilly. Exenatide summary of product characteristics. Available at http://www.emea.europa.eu/humandocs/PDFs/EPAR/byetta/H-698-PI-en.pdf. Accessed January 15, 2008.

Received 20 February 2008

Accepted 3 March 2008 